\title{
A Conceptual Framework of Designer Responses in Designing Furniture Application from Upcycled Plastic Materials
}

\author{
Fahmi Ahmad, Azroll Ahmad, Haszlin Saharudin, Hanif Khairi \\ Faculty of Art \& Design, \\ Universiti Teknologi MARA, 40450 Shah Alam Selangor, Malaysia \\ fahmiahmad@uitm.edu.my, mazroll870@uitm.edu.my, haszlin@uitm.edu.my, hanif@uitm.edu.my \\ Tel: 0126421674
}

\begin{abstract}
Understanding the design should be an emotion's role in various aspects of design, represent not only this research goal for research purpose but also for the successfulness of any design that has good philosophy. However, upcycling the solid waste plastic material to create another creative object could reduce the pollution issue and at the same time, support the awareness sustainability campaign. An underlying objective of this research understudy is to investigate and develop furniture application design, which will respond from designer and their experience. This is to contribute guidelines for the future development of new alternative material for furniture applications.
\end{abstract}

Keywords: Application, Furniture design, Designer response, Upcycling

eISSN: 2398-42870 2020. The Authors. Published for AMER ABRA cE-Bsby e-International Publishing House, Ltd., UK. This is an open access article under the CC BYNC-ND license (http://creativecommons.org/licenses/by-nc-nd/4.0). Peer-review under responsibility of AMER (Association of Malaysian Environment-Behaviour Researchers), ABRA (Association of Behavioural Researchers on Asians) and cE-Bs (Centre for Environment-Behaviour Studies), Faculty of Architecture, Planning \& Surveying, Universiti Teknologi MARA, Malaysia.

DOI: https://doi.org/10.21834/ebpj.v5iSI3.2532

\subsection{Introduction}

This research will focus on designing furniture applications to develop solutions for interesting and interactive furniture application design. The motivation needs of the upcycle plastic process are often not researched, addressed, and misunderstand. A few works of literature have been dictated on designing furniture application design by using upcycled plastic. There are so many examples that demonstrate the limitations of inadequate planning and designing a product from upcycling plastic material in Malaysia. In this research, the process method in transforming the waste plastic materials will be melt and moulded-in creating a new furniture application design. Therefore, the exploration and experimentation of the usage and the density of the waste plastic material can be transformed into a new furniture application design that can offer new potential material and image. This paper presents the conceptual framework of the methodology of the advantages of the upcycling process in recreating and reinventing the new product by user responses. The aim is to study and experiment with plastic waste material and its process-based design and design the new furniture application and designer responses.

\subsection{Upcycle Definition}

eISSN: 2398-4287@ 2020. The Authors. Published for AMER ABRA cE-Bsby e-International Publishing House, Ltd., UK. This is an open access article under the CC BYNC-ND license (http://creativecommons.org/licenses/by-nc-nd/4.0). Peer-review under responsibility of AMER (Association of Malaysian Environment-Behaviour Researchers), ABRA (Association of Behavioural Researchers on Asians) and cE-Bs (Centre for Environment-Behaviour Studies), Faculty of Architecture, Planning \& Surveying, Universiti Teknologi MARA, Malaysia.

DOI: https://doi.org/10.21834/ebpj.v5iSI3.2532 
The upcycle concept and definition can be defined as the reuse of the material or waste product to build another creative object to solve the current linear system of 'take-make-dispose' economy which generates enormous waste. The term upcycling was officially used by William Mc Donough and Michael Braungart (2002), and they solidified the definition of upcycling as a simple the method of real-world in the recycling of an old product into new ones by preventing waste.

The terms of upcycling are often confused with downcycling, which similar, but it's different in result. The current linear system of the "take-make-dispose" economy generates the enormous volume of waste and depleting environmental pollution, and the apparent solution to this issue is to reduce and reuse. Referring to Monika Nalewaje and Radosław Macik (2013), they explain that yet another motive interest in product reuse is the desire to look for useful solutions that simplify and organize somethings. In this section, it will conserve money and effort and time. The suitable phrase that can define the upcycle is the "creative reuse of waste" because it developed from human creativity to create an attractive object, a base from any waste material produced.

Mridula Harihar (2015) has mentioned, and he stated, by exploring and finding a new purpose of waste material that had been produced by extending the waste lifespan by preventing it from entering the landfill. Furthermore, the upcycle process involves creating a new product by using minimal input and less cost. Some researchers argue about upcycle because it is more on self-expression like the artwork, which is not a concern for the environment, but the detail in the making and selecting the material plus the technique is the answer for the argument. Victor Papanek (1995) has mentioned three words that can define the upcycle process: when the purpose of our designs are succinct statements, easy to use and understand, easy to repair and maintain, durable, environment friendly, and recyclable, we 'inform'. If we design with good ideas that involve harmony and balance in mind, working together for the good of the weaker members in our society, we 'reform'. Willing to face our design's effect, and accepting our moral and social responsibilities, we give 'form'. Reusing and re-purposing any material resource natural or man-made addresses the above mentioned INFORM, REFORM, and FORM effectively and simply.

\subsection{Plastic Waste in Malaysia}

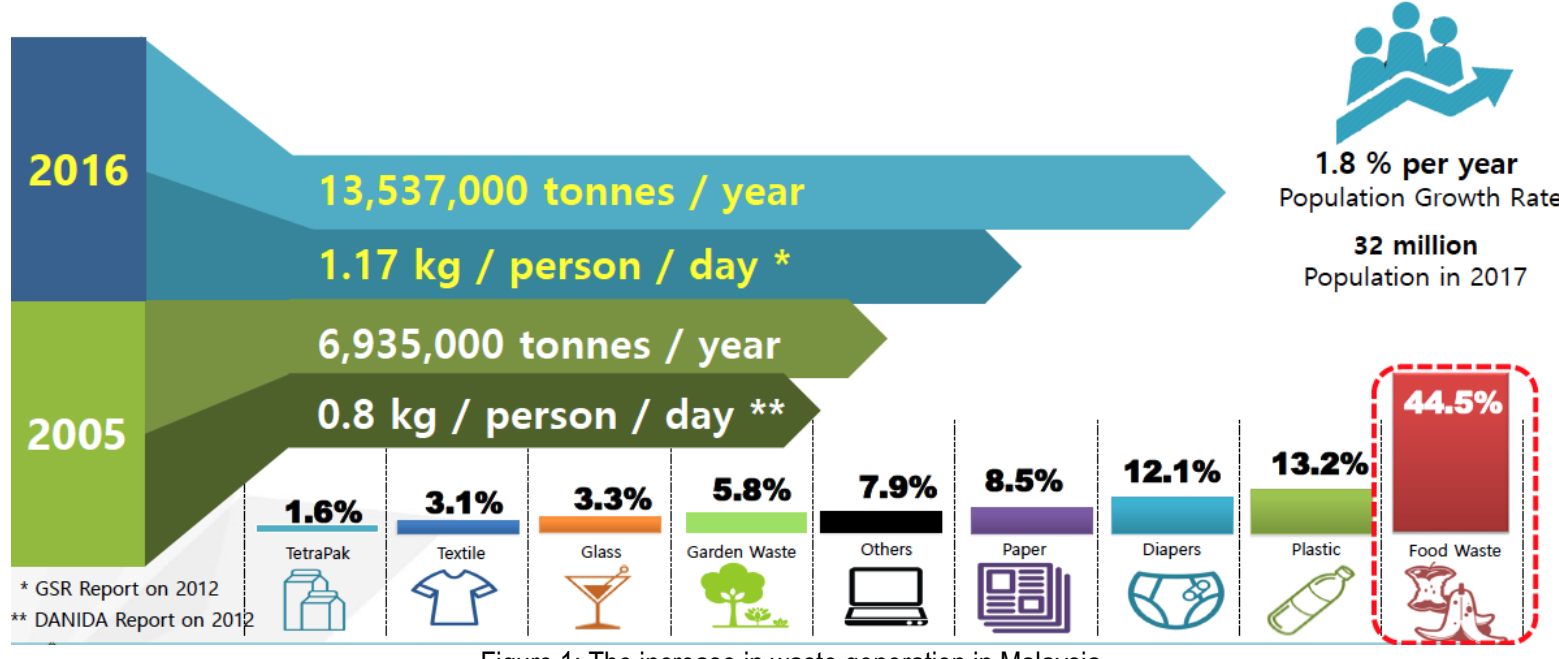

Figure 1: The increase in waste generation in Malaysia (http://www.swcorp.gov.my/)

\begin{tabular}{|l|c|c|c|c|c|c|}
\hline \multirow{2}{*}{ Country } & \multicolumn{7}{|c|}{ Types (in \%) } \\
\cline { 2 - 7 } & $\begin{array}{c}\text { Organic } \\
\text { waste }\end{array}$ & Paper & Plastic & Glass & Metal & Others \\
\hline Malaysia $^{a}$ & 45 & 7 & 24 & 3 & 6 & 15 \\
\hline Singapore $^{b}$ & 44.4 & 28.3 & 11.8 & 4.1 & 4.8 & 6.6 \\
\hline Thailand $^{b}$ & 48.6 & 14.6 & 13. & 5.1 & 3.6 & 14.2 \\
\hline China $^{b}$ & 35.8 & 3.7 & 3.8 & 2.0 & 0.3 & 54.3 \\
\hline Hong Kong $^{b}$ & 37.2 & 21.6 & 15.7 & 3.9 & 3.9 & 17.6 \\
\hline Indonesia $^{b}$ & 70.2 & 10.9 & 8.7 & 1.7 & 1.8 & 6.2 \\
\hline Japan $^{b}$ & 17.0 & 40.0 & 20.0 & 10.0 & 6.0 & 7.0 \\
\hline Laos $^{b}$ & 54.3 & 3.3 & 7.8 & 8.5 & 3.8 & 22.5 \\
\hline Myanmar $^{b}$ & 80.0 & 4.0 & 2.0 & 0.0 & 0.0 & 14.0 \\
\hline South Korea $^{b}$ & 31.0 & 27.0 & 6.0 & 5.0 & 7.0 & 23.0 \\
\hline Philippines $^{\mathrm{c}}$ & 50.0 & 12.0 & 25.0 & 3.0 & 5.0 & 5.0 \\
\hline
\end{tabular}

Table 1: Solid waste composition in Malaysia and other Asian countries.

(http://www.swcorp.gov.my/) 
In Malaysia, the solid waste statistic showed that every year the number is increased base on increasing the household in Malaysia. The table above shows that plastic waste is the second higher from overall plastic waste in Malaysia. The Malaysian government plans to reduce the waste that will end up to the landfill by proposed the other solution reusing the waste material and promoting the sustainable campaign.

A base report from National Solid Waste Management Department Ministry of Housing and Local Government Malaysia (2011) stated that Malaysia is the second-highest among the Asian countries that produced plastic waste. The report showed that Malaysia is struggling to manage the solid waste issue especially plastic material, and for the future with the new research and recycle campaign, and it hopes that Malaysia can reduce the solid waste problem.

\subsection{A Viewpoint on Designers' Roles}

Some of the designers are recognizing the diversity of users' needs and wants. However, the question is, whether or not users' want and needs to be satisfied without understanding how it operates. This study proposes that we change our attention from the design and the designer to the user. This change of attention is not intended to underrate the design since designers still need to play important roles. Nor does this change of attention only mean recognizing the diversity of users' wants and needs.

Siu (2003) has suggested that the designer should be able to define what they have to do in making the decisions for the user in the designing process. From this process, it can be described that they should not demand their value in judge on users. Many manufacturers invest in the market research to understand the user's needs with their preference for developing the new design and at the same time tested it extensively. In this context, this is the same that most of the design of the product especially useful in the environment, such as furniture must deal with the user's needs and desires. The serious consideration of different user groups' particular needs and preferences, particularly those of the minority groups. In recognizing that, they not allowed and cannot make arbitrary decisions for users need. Designers also should recognize the users right to get involve and modify designs to make them more suitable for their needs and desires. From these recognitions, there are alternatives, which designers should seriously consider allowing more "space" for users to fill and take part in and encourage users to develop the designs.

According to Sanoff (1992), we could categorize user participation in seven major forms: representation, questionnaires, regionalism, dialogue, alternative, co-decision, and self-decision. Representation is a design characteristic in which the designer represents the anonymous user through a personal and subjective interpretation of the user's situation".

\subsection{The Instrument in Measuring Designer's Response The Instrument in Measuring Designer's Response}

Semantic Differential (SD) is a measuring instrument to obtain the connotative value of an object or an image. The SD is used to find out designers' feel about the product. The product's design characteristics are identified from the designer's image and feelings by their studies or experiments in which the relations between words and design elements are observed. SD tries to explain which messages express or represent. Most of SD research is intended to help understand how human beings interpret the appearance, the use, and the content of the product. The SD is a scaling tool, which has been used frequently for measuring social attitudes, especially in the field of linguistics and social psychology, and Osgood, Suci, and Tannenbaum first devised it in 1957. Nowadays, it is widely used for "measuring the meaning of an object to an individual. The subject is asked to rate a given concept on a series of seven-point bipolar rating scales". Constructing bipolar scales based on semantic opposites, such as "beautiful - ugly", "angular - rounded", "high - low", "black-white," "wide - narrow" and so on. An example of an SD scale follows:

\section{$\begin{array}{lllllllllllll}\text { BEAUTIFUL } & 1 & 2 & 3 & 4 & 5 & 6 & 7 & 8 & 9 & 10 & \text { UGLY }\end{array}$}

This scale has the advantage that the subjects can indicate whether they judge the object as extremely beautiful or ugly by marking the extremities (1 or 10, respectively) or have not formed an opinion by marking position 4, a neutral position halfway between the two extremes. Using semantic scales that are designed to capture the emotional impact of design allows the candidate to understand how the product is 'plotted' in emotional space. Another vital advantage of using SD is that it is easily implemented and is not a complicated concept for laypeople to understand since the requirement is only for the subject to judge and circle a number.

There is an apparent need for designers and design researchers to conduct more theoretical and empirical research, especially when dealing with furniture applications designed for furniture application design based on the waste plastic material project. For instance, the complexity to understand designer's responses to a new effect on furniture application design is simply by producing one type of product based on the experiment activity (processing the waste plastic into the new product) in a simple focus group. Therefore, besides critically reviewing the literature in detail and experimenting with the density/potentially of the upcycle plastic waste and understanding the material characteristic and the process should also be tested in the lab. Material strength and its density reflect the long-term products of the design evolution, environment, culture, and other factors that will hopefully become apparent during this research. 


\subsection{The Framework of Study}

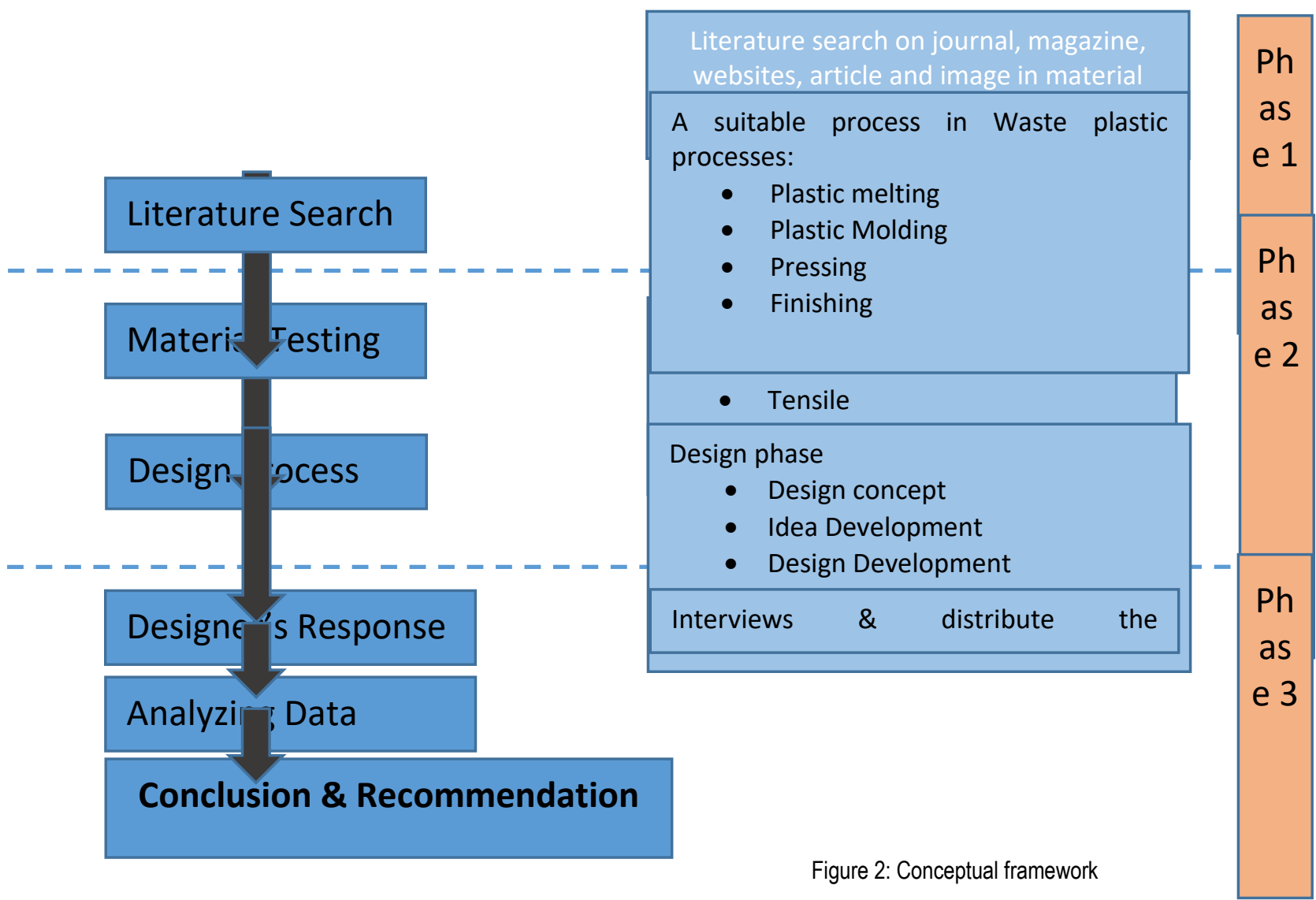

Methodology in design refers to the techniques and tools and assistance available to the designer to assist the research process. Green and Bonollo (2010) have emphasized that a design method usually describes models, principles, practices, and procedures that contribute to the design process's efficacy. The method(s) in design research may include methods related to the design process but, in general, it will also include qualitative and quantitative methods where empirical data obtained from interviews and field observations are processed, with appropriate software, in order to extract important concepts, principles, and guidelines that describe the social and cultural system being investigated.

Furniture design is a problem-solving and information processing activity where the objective is to develop a successful design fitting consumers' needs. To achieve this objective, in the first stage of this study, the writer will employ a systematic, qualitative research method based on data collection, analysis, synthesis, and decision-making by literature search on design concepts and trends. Specifically, this method will use the researcher's experience in designing by analysing the trends and referring to the material characteristics in developing the prototype.

The preselected designer's responses will provide qualitative data by interviewing, which will be analyzed for detailed insights into individuals' beliefs, experiences, and perceptions. Later, in the next stage of this fieldwork, the questionnaire will be distributed to the selected designer in a specific area to gain qualitative data. Two data that has been collected will be analyzed to measure the response and will be used as a guideline for the design based on waste plastic materials.

\subsection{Conclusion}

In conclusion, developing the design for the new furniture application design based on an upcycled plastic material requires a suitable design process and testing. This is because the upcycle plastic materials are easy to collect and to be processed. This conceptual framework paper will guide the designer and potential manufacturer to develop and use the upcycle plastic for their new product. On the other hand, this conceptual framework can also be used as one of the National agendas for the country to support the sustainable campaign and, at the same time, promise the economic growth index in supplying the product based on the upcycling plastic material. Furthermore, this research project is important because no manufacturer uses this concept to produce their product in Malaysia. Meanwhile, designers in developing the new product design can also use the guideline to propose the upcycle plastic materials as a potential material to apply for future their design project. At the end of this brief, the researcher hopes that this project will be done for further development with the different methods and techniques for developing and processing the new product development and process materials. 


\section{Acknowledgements}

The authors wish to thank Universiti Teknologi Mara, Malaysia as the main funder for the Bestari Perdana grants (600IRMI/PERDANA 5/3 BESTARI (110/2018) and allow the research team members to contribute the new knowledge in furniture design area in Malaysia. At the same time, the authors also wish to thank the research committee member who has advised the research plan and the research strategy.

\section{References}

Baxevanis, A. (n.d.). User-centred design: 6 popular UCD methods. Retrieved April 25, 2018, from https://inviqa.com/blog/user-centred- design-6-popular-ucd-methods.

Bonollo E. and Lewis W.P. (1996). The Industrial Design Profession and Model of the Design process Published: Design \& Education, Vol: 6, no. 2, DECA (Design and Education Council) Australia.

Bonollo, E. (2010). Product Design- A course in first principal, Australia. LB Publications, Canberra. Cranz, Galen (1998). The Chair: Rethinking Culture, Body, and Design, NY, Library of Congress Cataloguing in Publication Data.

Brower, Mallory, Ohlman (2005). Experimental Eco-Design Architecture/Fashion/Product. Switzerland. RotoVision SA.

Commercial Solid Waste Separation to be Done in Stages. (2019, August 9). Retrieved April 25, 2018, from http://www.swcorp.gov.my/

Designing with Waste. (2017, November 17). Retrieved April 25, 2018, from http://www.kabadiwallaconnect.in/blog/2015/11/17/designing-with-waste

Ekman P. Emotions Revealed, (2007) Second Edition: Recognizing Faces and Feelings to Improve Communication and Emotional Life. Holt Paperbacks

Green Tech Plan Spur Economy. (n.d.). Retrieved April 25, 2018, from http://www.nst.com.my/news/2015/09/'green-tech-plan-spur-Economy

Potter, Norman (2002). What Is a Designer: Things? Place. Messages, Fourth Edition, Published by Hypen Press, London, (Www.Hypenpress.Co.Uk)

Lawson, Bryan (1997). How Designers Think: The Design Process Demystified, Architectural Press, Oxford, British Library Cataloguing in Publication Data.

Lewis, W.P., \& Bonollo, E. (2002). An Analysis of Professional Skill in Design: Implications for Education and Research. University of Melbourne and University of Canberra, Australia, Published by Elsevier Science Ltd.

Koo Kim, C. (1995). Brand popularity and country image in global competition: managerial implications. Journal of Product \& Brand Management, 4(5), 21-33.

McDonough, William; Braungart, Michael (2002). Cradle to Cradle: Remaking the Way We Make Things: North Point Press.

Heskett, J. (1980). 'Industrial Design'; Oxford University Press, New York \& Toronto; Thames and Hudson. Longdon, R. (1984) (edition). Design and Industry, The Design Council London.

Siu, K.W.M (2003), Users' Creative Responses and Designers' Roles, Massachusetts Inst. of Tech. Design Issues: Vol 19, №. 2 spring.

History of Upcycling. (2020, April 25). Retrieved April 25, 2018, from https://treepeace.com/pages/history-of-upcycling

Victor Papanek., (1995). Toward the Spiritual in Design. The Green Imperative (pp.53). United Kingdom: Thames \& Hudson.

W.P Lewis \& E. Bonollo (2002). An Analysis of Professional Skill in Design: Implications for Education and Research. University of Melbourne and University of Canberra, Australia, Published by Elsevier Science Ltd. 